\title{
DEVELOPMENT AND VALIDATION OF A STABILITY-INDICATING HPLC METHOD FOR THE DETERMINATION OF BUCLIZINE HYDROCHLORIDE IN TABLETS AND ORAL SUSPENSION AND ITS APPLICATION TO DISSOLUTION STUDIES
}

\author{
Gislaine Kuminek*, Hellen K. Stulzer, Monika P. Tagliari, Paulo R. Oliveira, Larissa S. Bernardi, Gabriela Rauber e \\ Simone G. Cardoso \\ Departamento de Ciências Farmacêuticas, Universidade Federal de Santa Catarina, Campus Universitário Reitor João David \\ Ferreira Lima, 88040-900 Florianópolis - SC, Brasil
}

Recebido em 10/3/11; aceito em 24/5/11; publicado na web em 22/7/11

\begin{abstract}
A method using liquid chromatography has been developed and validated for determination of buclizine in pharmaceutical formulations and in release studies. Isocratic chromatography was performed on a C18 column with methanol:water (80:20 v/v, $\mathrm{pH}$ 2.6) as mobile phase, at a flow rate of $1.0 \mathrm{~mL} / \mathrm{min}$, and UV detection at $230 \mathrm{~nm}$. The method was linear, accurate, precise, sensible and robust. The dissolution test was optimized and validated in terms of dissolution medium, apparatus agitation and rotation speed. The presented analytical and dissolution procedures can be conveniently adopted in the quality and stability control of buclizine in tablets and oral suspension.
\end{abstract}

Keywords: buclizine; dissolution test; liquid chromatography.

\section{INTRODUCTION}

Buclizine Hydrochloride (BCZ), (RS)-1-(4-tert-butylbenzyl)-4(4-chlorobenzhydryl)piperazine dihydrochloride (Figure 1), ${ }^{1}$ is a piperazine derivative having antihistaminic, antimuscarinic, antiemetic and moderate sedative properties. BCZ, as its analogue meclizine, is mainly used in the prevention of motion sickness, nausea, vomiting, with analgesics in the treatment of migraine and as an appetite stimulant due to its orexigenic effect. This drug has also been used in the treatment of vertigo associated with disorders of the vestibular system, although its value in these conditions remains to be established. ${ }^{1-3}$<smiles>CC(C)(C)c1ccc(CN2CCN(C(c3ccccc3)c3ccc(Cl)cc3)CC2)cc1</smiles>

Figure 1. Chemical structure of buclizine

Analytical methods have been published for the analysis of BCZ in tablet and human serum by $\mathrm{LC}^{4,5}$ and by spectrophotometry. ${ }^{6}$ However, these methods lack stability indicating nature. Stability indicating methods can detect changes with time of drug substances and drug products. Information of degradation products over time is important for safety of drugs. ${ }^{7}$ Moreover, the published methods were not applied for oral suspension or for in vitro dissolution studies. This is important because the quality of oral solid pharmaceutical dosage forms depends on their ability to release the active ingredients in aqueous media in a consistent and reproducible manner, making the active substances available for gastrointestinal absorption. Therefore, the performance of oral solid dosage forms should be verified preferably with an in vitro dissolution test before the product is released to the market. ${ }^{8}$ The dissolution test has emerged as a valuable quality control tool to assess batch-to-batch product release performance and

*e-mail: giskuminek@gmail.com detection of manufacturing deviations. Besides, it may be relevant to the prediction of in vivo performance of the drug. In addition, dissolution is a requirement for regulatory approval for product marketing. ${ }^{9-12}$ At the moment, no dissolution test has been described in literature for BCZ. The present work has two main objectives. The first is to develop and validate a stability-indicating method for determination of BCZ in tablets and oral suspension. The second objective is to apply the assay to the optimization and validation of dissolution test.

\section{EXPERIMENTAL}

\section{Reagents and chemicals}

BCZ standard was kindly donated by Medley (Campinas, SP, Brazil). Tablets and oral suspension where purchased at the local market. The tablets $\left(\operatorname{Profol}^{\circledR}\right.$ ) labeled to contain $25 \mathrm{mg}$ of the BCZ, $20 \mathrm{mg}$ of tryptophan, $20 \mathrm{mg}$ of pyridoxine hydrochloride, $50 \mu \mathrm{g}$ of cyanocobalamin and the excipients: talc, dibasic calcium phosphate dehydrate, povidone, magnesium stearate and starch. The oral suspension $\left(\right.$ Profol $^{\circledR}$ ) labeled to contain $1 \mathrm{mg} / \mathrm{mL}$ of BCZ, $2 \mathrm{mg} / \mathrm{mL}$ of tryptophan, $2 \mathrm{mg} / \mathrm{mL}$ of pyridoxine hydrochloride and $5 \mu \mathrm{g} / \mathrm{mL}$ of cyanocobalamin and the excipients: hydrochloric acid, sodium cyclamate, methylparaben, propylparaben, polysorbate 80 , propylene glycol, simethicone, sorbitol, sodium tartatre, cysteine hydrochloride monohydrate and deionized water. Sodium lauryl sulfate (SLS) was from Vetec (Rio de Janeiro, RJ, Brazil). HPLC-grade methanol was obtained from Tedia (Fairfield, OH, USA). Phosphate and acetate buffer solutions were prepared according to USP. ${ }^{13}$ For all the analyses, ultrapure water was obtained from Milli- $\mathrm{Q}^{\circledR}$ apparatus (Millipore, Bedford, MA, USA). All chemicals used were of pharmaceutical or special analytical grade.

\section{HPLC method}

Chromatographic analyses were performed with a Shimadzu LC 10A vp system (Shimadzu, Kyoto, Japan). The UV detector was set at $230 \mathrm{~nm}$ and peak areas were integrated automatically by computer using a Shimadzu Class VP V 6.14 software program. The 
experiments were carried out on a reversed-phase Waters Corporation (Ireland) X-Bridge $\mathrm{C}_{18}$ column (250 $\mathrm{mm}$ x $4.6 \mathrm{~mm}$ I.D., $5 \mu \mathrm{m}$ ), maintained at $25 \pm 1{ }^{\circ} \mathrm{C}$. The mobile phase consisted of a mixture of methanol and water (80:20, v/v) at pH 2.6 adjusted with phosphoric acid, was eluted isocratically at a $1.0 \mathrm{~mL} / \mathrm{min}$ flow rate. The injection volume was $20 \mu \mathrm{L}$ and the retention time was about $6 \mathrm{~min}$.

\section{Preparation of standard solution}

A standard stock solution containing $1 \mathrm{mg} / \mathrm{mL}$ of BCZ chemical reference standard was prepared in mobile phase. This solution was kept refrigerated and protected from light. Working solutions were prepared by diluting the stock solution as appropriate in mobile phase or dissolution medium depending on the analysis.

\section{Preparation of sample solutions}

Tablets

Twenty tablets were weighted and finely powdered. An amount of tablet equivalent to $50 \mathrm{mg}$ of $\mathrm{BCZ}$ was accurately weighted, transferred into a $50 \mathrm{~mL}$ volumetric flask and $30 \mathrm{~mL}$ of the mobile phase was added. The solution was subjected to sonication for 45 min, brought to volume with mobile phase, and filtered through a $0.45 \mu \mathrm{m}$ nylon membrane. Finally, $700 \mu \mathrm{L}$ of the filtered solution was directly transferred to a $50 \mathrm{~mL}$ volumetric flask and diluted to volume with mobile phase obtaining the final concentration of $14 \mu \mathrm{g} / \mathrm{mL}$.

\section{Oral suspension}

The suspension vial was stirred on a magnetic stir plate during 2 min to assure the homogeneity at the time to take the aliquot. An aliquot of $700 \mu \mathrm{L}$ of the suspension was quantitatively transferred to a $50 \mathrm{~mL}$ volumetric flask containing $30 \mathrm{~mL}$ of mobile phase, and stirred in an ultrasonic bath for $45 \mathrm{~min}$. The volume was completed with the mobile phase to obtain the final concentration of $14 \mu \mathrm{g} /$ $\mathrm{mL}$, and the resulted solution was filtered through a $0.45 \mu \mathrm{m}$ nylon membrane before use.

\section{Validation of the HPLC method}

\section{Specificity}

In order to determine the specificity of the method, the absence of interference was checked by the placebo solution (tablets and oral suspension only with excipients and other combined drugs). Moreover, the specificity was determined according to $\mathrm{ICH}^{14}$ by the accelerated degradation. The stability-indicating capability of the method was determined by subjecting a standard stock solution $(1000 \mu \mathrm{g} / \mathrm{mL})$ to accelerated degradation by acidic, basic, oxidative, and photolytic conditions. It was taken $2 \mathrm{~mL}$ from this solution and transfered to $10 \mathrm{~mL}$ volumetric flask and brought to volume with $2 \mathrm{M}$ hydrochloric acid, $2 \mathrm{M}$ sodium hydroxide and $30 \%$ hydrogen peroxide to achieve a concentration of $200 \mu \mathrm{g} / \mathrm{mL}$. The studies in acid conditions were carried out under reflux at $80{ }^{\circ} \mathrm{C}$ for $4 \mathrm{~h}$, and the solution was cooled at room temperature and neutralized with base. The alkaline degradation was induced by storing the samples solutions under reflux at $80{ }^{\circ} \mathrm{C}$ for $4 \mathrm{~h}$, cooled at room temperature and neutralized with acid. Oxidative degradation was obtained by treating the drug with $30 \%$ hydrogen peroxide, maintaining it protected from light at ambient temperature for $48 \mathrm{~h}$. Photodegradation was achieved by exposing the standard solution in a photostability chamber to $200 \mathrm{~W} \mathrm{~h} / \mathrm{m}^{2}$ of near ultraviolet light for $48 \mathrm{~h}$. After the described treatments, all the samples were diluted to $14 \mu \mathrm{g} / \mathrm{mL}$ with mobile phase, and analyzed.

\section{Linearity}

Linearity was determined by constructing three independent calibration curves. For the construction of each calibration curve 5 standard concentrations of BCZ in the range of $0.5-24 \mu \mathrm{g} / \mathrm{mL}$ were prepared using stock solution and mobile phase. The solutions were injected in triplicate and the linearity was estimated by linear regression.

\section{Limits of quantitation and detection}

The quantification limit (LOQ) and detection limit (LOD) were based on the standard deviation of the response and the slope of the mean of three calibration curves, as described in $\mathrm{ICH} .{ }^{14}$

\section{Accuracy}

Accuracy of the LC method was evaluated by the recovery test of known amounts of the standard added to a sample solution (containing the excipients and $7 \mu \mathrm{g} / \mathrm{mL}$ of BCZ) to obtain solutions with final concentrations corresponding to 80,100 and $120 \%$ of the nominal analytical concentration. The accuracy was calculated as the percentage of drug recovered from the formulation matrix.

\section{Precision}

The precision assay was investigated with respect to repeatability (intra-day) and intermediate precision (inter-day). The repeatability was evaluated by assaying 6 tablets and oral suspension samples $(14 \mu \mathrm{g} / \mathrm{mL})$, during the same day and under the same experimental conditions. The intermediate precision was assessed by carrying out the same analysis on 3 different days. The precisions were expressed as \% RSD.

\section{Robustness}

The robustness of the developed method was examined against small and deliberate variations of critical parameters such as $\mathrm{pH}$, composition of the mobile phase, flow rate and column temperature.

\section{System suitability}

The system suitability was evaluated by six replicate analyses of a BCZ solution at a concentration of $14 \mu \mathrm{g} / \mathrm{mL}$. The calculated parameters were: peak area $\%$, retention time, number of theoretical plates and tailing factor.

\section{Dissolution testing}

\section{Dissolution study}

The development and validation of the dissolution test was performed using a Varian dissolution test system, model VK 7000 multi-bath $(n=8)$ in accordance to USP Pharmacopoeia ${ }^{13}$ general method. All the dissolution samples were analyzed by LC assay as described above.

\section{Solubility determination and sink conditions}

The sink conditions were determined in different media. 0.01, 0.1 $\mathrm{M} \mathrm{HCl}$, aqueous solution with $0.5 \%$ of sodium lauryl sulfate (SLS), aqueous solution with $1.0 \%$ of SLS, aqueous solution with $1.5 \%$ of SLS, phosphate buffer $\mathrm{pH} 6.8$ and acetate buffer $\mathrm{pH} 4.1$ were tested. Vessels $(n=3)$ containing $240 \mathrm{~mL}$ of medium were pre-heated to 37 $\pm 0.5^{\circ} \mathrm{C}$ before adding an excess of BCZ $(20 \mathrm{mg})$. The samples were gently rotated. Aliquots $(5 \mathrm{~mL})$ were withdrawn from each vessel after 1 and $2 \mathrm{~h}$, filtered, neutralized, and analyzed.

\section{Dissolution test conditions}

The influence of different apparatus (USP basket and paddle) and different rotation speeds were evaluated. The medium volume used 
was $900 \mathrm{~mL}$ pre-heated to $37 \pm 0.5^{\circ} \mathrm{C}$. The dissolution medium $\mathrm{pH}$ was monitored before and after the performance of the tests. Sample aliquots of $10 \mathrm{~mL}$ were withdrawn at 5, 10, 15, 20, 30, 60, 90 and 120 min and replace with an equal volume of fresh medium to maintain a constant total volume. After the end of each test time, samples aliquots were filtered, diluted in methanol $(1: 1, \mathrm{v} / \mathrm{v})$ and quantified. The assay of the tablets and oral suspension was performed using the validated LC method and the contents results were used to calculate the percentage of drug released on each time of dissolution profile. The cumulative percentage of drug released was plotted against time, in order to obtain the release profile and to calculate the in vitro dissolution data. BCZ stability in dissolution medium was evaluated using the same test conditions. Aliquots of the samples were tested after $2 \mathrm{~h}$. The responses for the solutions were evaluated comparing with a freshly prepared standard. The assay was performed in triplicate. The filtration of BCZ standard and samples (tablets and oral suspension dissolved in dissolution medium) was evaluated using $0.45 \mu \mathrm{m}$ cellulose acetate membrane filter (Vertical, Thailand), quantitative filter (J. Prolab, Brazil) and cellulose membrane filter together with quantitative filter. Unfiltered (centrifuged) solution was not evaluated because it could damage the column.

\section{Validation of the dissolution method}

The developed dissolution test was validated for specificity, linearity, accuracy, and precision according to ICH guidelines and US Pharmacopoeia. ${ }^{13,14}$

\section{Specificity}

Specificity was evaluated by preparing samples of placebo which consisted of all excipients present in formulations. Their concentrations were determined based in Handbook of Pharmaceutical Excipients ${ }^{15}$ and calculated for medium weight content. The samples of placebo were transferred to separate vessels $(n=3)$, filled with 900 $\mathrm{mL}$ of dissolution medium at $37 \pm 0.5{ }^{\circ} \mathrm{C}$ and stirred for $120 \mathrm{~min}$ at $100 \mathrm{rpm}$ using basket. Samples aliquots were filtered, diluted in methanol (1:1, v/v) and analyzed.

\section{Linearity}

The nominal concentration of BCZ after the dissolution experiments - assuming quantitative dissolution - is $27.8 \mu \mathrm{g} / \mathrm{mL}(25 \mathrm{mg}$ BCZ per tablet or $25 \mathrm{~mL}$ of a suspension $(1 \mathrm{mg} / \mathrm{mL})$ in $900 \mathrm{~mL}$ of dissolution medium). Before the injection, these solutions were diluted in methanol $(1: 1, \mathrm{v} / \mathrm{v})$, to obtain good peak resolution, to a final concentration of $13.9 \mu \mathrm{g} / \mathrm{mL}$. In order to bracket effectively the above mentioned concentration, linearity was validated in the range of $0.5-24 \mu \mathrm{g} / \mathrm{mL}$, in dissolution medium, corresponding to approximately $4-180 \%$ of the target value.

\section{Accuracy}

The accuracy of the dissolution method was evaluated by the recovery of known amounts of $\mathrm{BCZ}$ added to placebo. Aliquots of 5,25 and $30 \mathrm{~mL}$ of a $1 \mathrm{mg} / \mathrm{mL} \mathrm{BCZ}$ standard solution dissolved in mobile phase was added to vessels containing dissolution medium for a final volume of $900 \mathrm{~mL}$ (final concentrations were 5.5, 27.8 and $33.3 \mu \mathrm{g} / \mathrm{mL}$, respectively), and subjected to the dissolution test conditions described above. Placebo samples were prepared in the same way previously described in the specificity test.

\section{Precision}

The precision was determined by measuring the repeatability (intra-day) and the intermediate precision (inter-day), both expressed as \% RSD. Tablets and oral suspension were subjected to dissolution test conditions $\left(900 \mathrm{~mL}\right.$ of dissolution medium pre-heated at $37{ }^{\circ} \mathrm{C} \pm$ 0.5 , basket with stirring rate of $100 \mathrm{rpm}$ for tablets and paddle with stirring rate of $25 \mathrm{rpm}$ for oral suspension, both for $120 \mathrm{~min}$ ) in the same day and in three different days.

\section{RESULTS AND DISCUSSION}

\section{HPLC method}

To obtain the best chromatographic condition, the mobile phase was optimized to provide adequate peak symmetry and sensitivity. Methanol, acetonitrile and water in different proportions were tested. The method proposed by Arayne et al. was also considered. The optimal results were achieved with a mobile phase of methanol in combination with water $(80: 20, \mathrm{v} / \mathrm{v}) \mathrm{pH}$ adjusted to 2.6 with phosphoric acid, at a flow rate of $1 \mathrm{~mL} / \mathrm{min}$ and $25^{\circ} \mathrm{C}$ of column temperature. In optimized chromatographic conditions the $\mathrm{BCZ}$ retention time was about $5.8 \mathrm{~min}$, and a typical chromatogram obtained by the proposed method is shown in Figure 2a.
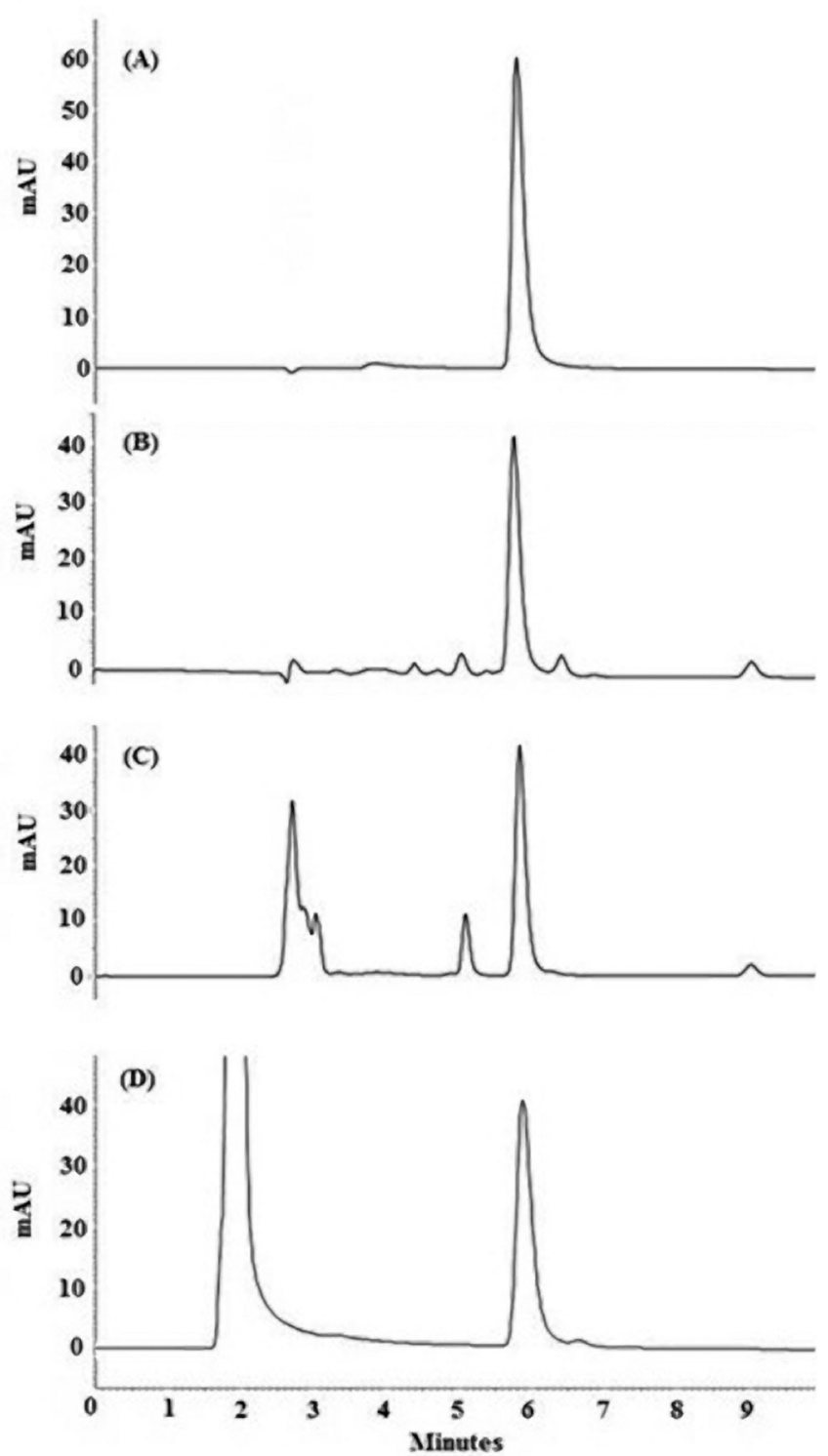

Figure 2. Chromatograms obtained under stress studies. (A) BCZ standard (14 $\mu \mathrm{g} / \mathrm{mL})$ ); (B) after photolytic degradation (UV 254nm); (C) after acid hydrolysis $(2 \mathrm{M} \mathrm{HCl}) ;(D)$ after oxidative $\left(30 \% \mathrm{H}_{2} \mathrm{O}_{2}\right)$ degradation 
The chromatograms obtained with specificity test (not shown) showed that there is no interference or overlap of the excipients with the BCZ peak. Furthermore, specificity was confirmed through the stress study. These studies were performed to validate stability indicating capability of the developed method and to identify the key factors which will impact the stability of the drug product. The alkaline condition was excluded from the study, due to the fact that $\mathrm{BCZ}$ is insoluble in this condition of $\mathrm{pH}$ and precipitates, which makes impossible to quantify it. In this way, the stress study was performed only with photolytic, acid and oxidative conditions. Under photolytic conditions $91 \%$ of $\mathrm{BCZ}$ remained, and four well-separated degradations products were detected (Figure $2 b$ ). After acid hydrolysis the $\mathrm{BCZ}$ content decreased and two additional peaks were observed at 5 and 9 min (Figure 2c). Peaks at approximately 3 min correspond to $\mathrm{HCl}$. The degradation of $\mathrm{BCZ}$ in acid conditions was found to be about $27 \%$ after $4 \mathrm{~h}$ of study. From the results of the oxidative studies (Figure $2 \mathrm{~d}$ ), it was observed only $0.7 \%$ of degradation without any additional peak. Peak at $2.8 \mathrm{~min}$ is due to $\mathrm{H}_{2} \mathrm{O}_{2}$. All additional peaks were resolved from $\mathrm{BCZ}$ peak.

The calibration curves constructed for $\mathrm{BCZ}$ were obtained by plotting peak area ratio against the concentration of the drug. Good linearity was observed in the 0.5 to $24 \mu \mathrm{g} / \mathrm{mL}$ range. The response for the drug was linear and the calibration equation was $y=37657 x$ - 9081 (where, $x$ is concentration and $y$ is the peak absolute area), which showed good correlation coefficient $(\mathrm{r}=0.9995)$ and intercept not different from $0(p>0.05)$. The detection and quantification limits were $0.06 \mu \mathrm{g} / \mathrm{mL}$ and $0.21 \mu \mathrm{g} / \mathrm{mL}$ respectively, showing the sensibility of the method.

Mean recovery of BCZ standard for low, medium and high level were, respectively, 98.5, 98.6 and $99.8 \%$ for tablets and 100.5, 100.2 and $101.2 \%$ for oral suspension, satisfying the acceptance criteria for the study.

A satisfactory intra-day and inter-day variability was obtained, as can be observed in Table 1. The amounts of BCZ found on 3 different days were equivalent ( $p>0.05$ ), and RSD values were found to be below $2.0 \%$.

The degree of reproducibility of the results obtained as a result of small deliberate variations in the method parameters has proven that the method is robust and the data are summarized in Table 2.

The results obtained with system suitability tests confirmed that chromatographic system was adequate for the analyses. The RSD of peak area $(0.46 \%)$ and retention time $(0.04 \%)$ are within $2 \%$. The efficiency of the column as expressed by number of theoretical plates was 5520 and the tailing factor was 1.26 .
Table 1. Intra-day and inter-day precision data of the LC method fo $\mathrm{r} \mathrm{BCZ}$

\begin{tabular}{|c|c|c|c|}
\hline \multirow{2}{*}{ Sample } & \multicolumn{2}{|r|}{ Intra-day } & \multirow{2}{*}{$\begin{array}{c}\text { Inter-day } \\
\mathrm{RSD}^{\mathrm{b}}\end{array}$} \\
\hline & Day & Recovery $^{\mathrm{a}}(\%) \pm \mathrm{RSD}^{\mathrm{b}}$ & \\
\hline \multirow[t]{3}{*}{ Tablet } & 1 & $100.5 \pm 0.30$ & 0.75 \\
\hline & 2 & $99.3 \pm 0.68$ & \\
\hline & 3 & $100.6 \pm 0.64$ & \\
\hline \multirow[t]{3}{*}{ Oral Suspension } & 1 & $101.5 \pm 0.26$ & 0.59 \\
\hline & 2 & $100.3 \pm 0.42$ & \\
\hline & 3 & $101.0 \pm 0.09$ & \\
\hline
\end{tabular}

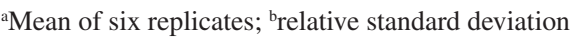

\section{Dissolution testing}

Solubility data were used as the basis for the selection of a dissolution medium for BCZ. Drug solubility was determined in different media, using an amount of the drug equivalent a three times of the dose in the pharmaceutical formulations. According to Table 3, aqueous solution with $1.5 \%$ of SLS was the best medium for the BCZ dissolution test and also ensured sink conditions. In this medium, BCZ was stable for $2 \mathrm{~h}$ (variation less than $2 \%$ ). The filter evaluation is necessary to determine if it could be used in the dissolution test without adsorption of the drug. Besides, it removes insoluble excipients that may otherwise cause high background or turbity. ${ }^{16}$ The quantitative and $0.45 \mu \mathrm{m}$ cellulose acetate filters showed recoveries between $98-102 \%$. Nevertheless, due to low cost of quantitative filter when compared to $0.45 \mu \mathrm{m}$ cellulose acetate filter, the first one was chosen.

\section{Dissolution profile of tablets}

The selection of the dissolution medium was based on the solubility data. Figure 3 shows the dissolution profiles of BCZ tablets obtained in $900 \mathrm{~mL}$ of aqueous solution with $1.5 \%$ of SLS medium in rotation speeds of 50,75 and $100 \mathrm{rpm}$ using basket and 50 and $75 \mathrm{rpm}$ using paddle $(n=6)$. It was observed that more than $80 \%$ of drug was dissolved at $120 \mathrm{~min}$ in basket 75 and $100 \mathrm{rpm}$. In the other conditions the $\%$ drug dissolved was $<75 \%$. The analysis of variance of the dissolution efficiency (DE\%) showed significant difference $(p$ $<0.05)$ between the results obtained at 75 and $100 \mathrm{rpm}(67.2$ and $75.8 \%$, respectively). It was observed that drug release percent and the DE were higher at $100 \mathrm{rpm}$. Basket apparatus is recommended, as a general rule, for dissolution test of capsules. However, by using

Table 2. Chromatographic conditions and range investigated during robustness testing for BCZ

\begin{tabular}{|c|c|c|c|}
\hline Variable & Range investigated & Tablets assay $\% \pm \mathrm{RSD}^{\mathrm{b}}$ & Oral suspension assay $\% \pm \mathrm{RSD}^{\mathrm{b}}$ \\
\hline \multirow[t]{3}{*}{ Flow rate $(\mathrm{mL} / \mathrm{min})$} & 0.8 & $100.2 \pm 1.05$ & $101.4 \pm 1.20$ \\
\hline & 1.0 & $100.3 \pm 0.49$ & $100.9 \pm 0.65$ \\
\hline & 1.2 & $98.0 \pm 0.77$ & $98.7 \pm 0.56$ \\
\hline \multirow[t]{3}{*}{ Column temperature $\left({ }^{\circ} \mathrm{C}\right)$} & 25 & $100.1 \pm 0.34$ & $100.2 \pm 0.44$ \\
\hline & 30 & $100.7 \pm 0.22$ & $100.8 \pm 0.37$ \\
\hline & 40 & $100.5 \pm 0.12$ & $100.9 \pm 0.28$ \\
\hline \multirow[t]{3}{*}{ Mobile phase $\mathrm{pH}$} & 2.4 & $98.1 \pm 0.96$ & $99.0 \pm 0.98$ \\
\hline & 2.6 & $99.7 \pm 0.63$ & $100.3 \pm 0.39$ \\
\hline & 2.8 & $97.8 \pm 0.75$ & $98.7 \pm 0.47$ \\
\hline
\end{tabular}

${ }^{a}$ Mean of three replicates; brelative standard deviation 
Table 3. Percent of buclizine dissolved in different media

\begin{tabular}{lcc}
\hline Medium & \multicolumn{2}{c}{$\%$ Dissolved } \\
\cline { 2 - 3 } & $1 \mathrm{~h}$ & $2 \mathrm{~h}$ \\
\hline $0.01 \mathrm{M} \mathrm{HCl}$ & 7.6 & 14.4 \\
$0.1 \mathrm{M} \mathrm{HCl}$ & 55.5 & 68.3 \\
Phosphate buffer (pH 6.8) & 40.7 & 43.9 \\
Acetate buffer (pH 4.1) & 1.8 & 2.0 \\
Aqueous solution with 0.5\% of SLS & 4.2 & 7.5 \\
Aqueous solution with 1.0\% of SLS & 28.1 & 43.2 \\
Aqueous solution with 1.5\% of SLS & 67.3 & 99.0 \\
\hline
\end{tabular}

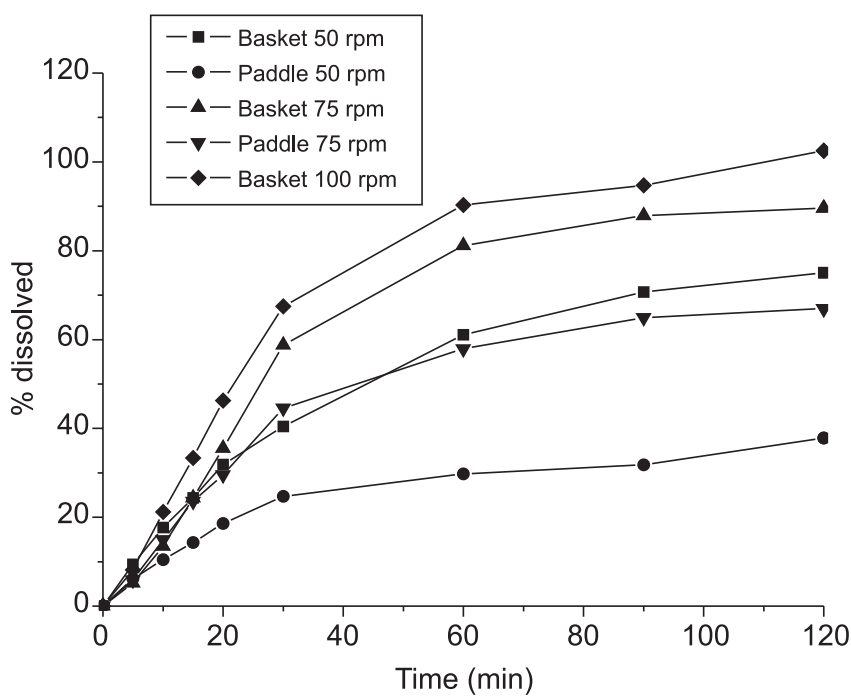

Figure 3. Dissolution profiles of buclizine tablets in aqueous solution with $1.5 \%$ of sodium lauryl sulfate medium using basket (50, 75 and $100 \mathrm{rpm}$ ) and paddle (25 and $50 \mathrm{rpm}$ )

paddle apparatus the $\mathrm{BCZ}$ tablets have adhered on the bottom of the vessel, making it unable to use. In this way, aqueous solution with $1.5 \%$ of SLS medium and basket in rotation speed of $100 \mathrm{rpm}$ were the conditions selected for the dissolution test of tablets.

\section{Dissolution profile of oral suspension}

Figure 4 shows the dissolution profiles of $\mathrm{BCZ}$ oral suspension in $900 \mathrm{~mL}$ of aqueous solution with $1.5 \%$ of SLS medium in rotation speeds of 25 and $50 \mathrm{rpm}$, using paddle apparatus. The statistical analysis at 0.05 significance level showed significant difference between the DE of 25 and $50 \mathrm{rpm}$ (84.3 and 91.7, respectively).Using $50 \mathrm{rpm}$ the dissolution proceeds too quickly, almost $100 \%$ of the drug was dissolved in $30 \mathrm{~min}$. On the other hand, rotational speed of $25 \mathrm{rpm}$ produced a better discriminating dissolution profile. Based in these results, the selected rotation for dissolution test validation was $25 \mathrm{rpm}$.

\section{Validation of dissolution test}

The chromatogram obtained through the injection of placebo solution did not present any other peak in the same retention time of BCZ. According to the USP Forum ${ }^{16}$ the lack of chromatographic peaks from the placebo formulation demonstrates the specificity of the method.

The representative linear equation was $y=34083 x-5074$ (where, $x$ is concentration and $y$ is the peak absolute area) and the correlation coefficient was $r=0.9990$, indicating good linearity. The validity of the assay was verified by means of ANOVA, which demonstrated significant linear regression and non-significant linearity deviation $(p$

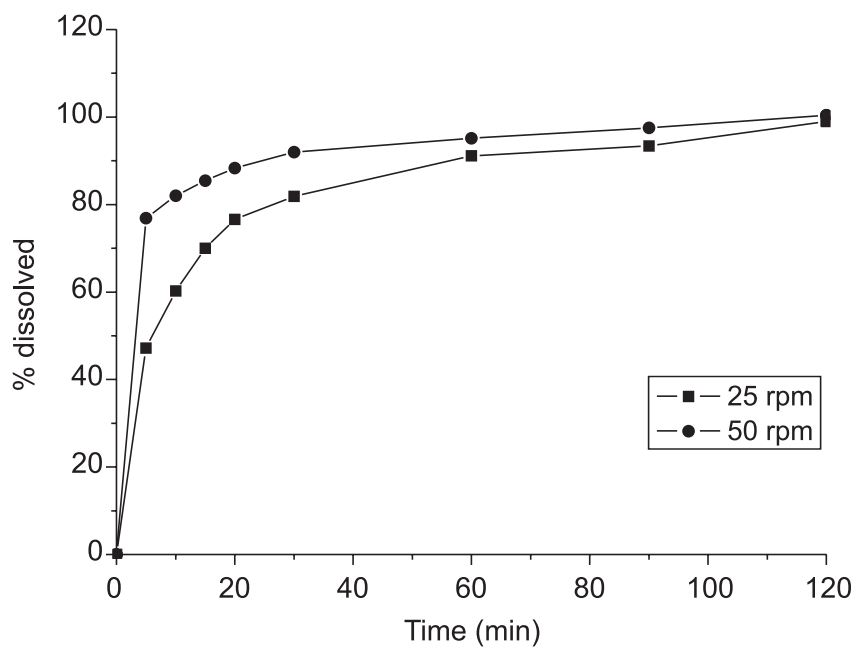

Figure 4. Dissolution profiles of buclizine oral suspension in 1.5\% sodium lauryl sulfate medium using paddle at 25 and $50 \mathrm{rpm}$

$>0.05)$. In the accuracy test, the mean recovery percentages for low, medium and high level were, respectively, 96.9, 101.8 and $100.4 \%$ for tablets and $104.5,101.3$ and $103.9 \%$ for oral suspension, confirming the accuracy of the method.

All the data for the repeatability and intermediate precision (Table 4) are within the acceptance criteria of $5 \% .^{16}$

Table 4. Intra-day and inter-day precision data of the dissolution method for $\mathrm{BCZ}$

\begin{tabular}{lccc}
\hline Sample & \multicolumn{2}{c}{ Inter-day } & \begin{tabular}{c} 
Intra-day \\
\cline { 2 - 3 }
\end{tabular} \\
\cline { 2 - 3 } Tablet & Day & Recovery $^{\mathrm{a}}(\%) \pm \mathrm{RSD}^{\mathrm{b}}$ & \\
& 1 & $99.6 \pm 1.71$ & 1.13 \\
& 2 & $99.5 \pm 1.50$ & \\
Oral Suspension & 3 & $101.5 \pm 0.92$ & \\
& 1 & $101.2 \pm 0.31$ & 0.17 \\
& 2 & $101.2 \pm 0.23$ & \\
& 3 & $101.5 \pm 0.41$ & \\
\hline
\end{tabular}

${ }^{\mathrm{a}}$ Mean of 6 replicates; ${ }^{\mathrm{b}}$ relative standard deviation

\section{CONCLUSIONS}

A stability-indicating LC method was developed and validated to the routine quality control of $\mathrm{BCZ}$ in pharmaceutical formulations and was satisfactory in the quantitation of $\mathrm{BCZ}$ tablets and oral suspension from the dissolution tests. The method showed to be specific, linear, accurate, precise, sensible and robust. In dissolution test, the use of $900 \mathrm{~mL}$ of aqueous solution with $1.5 \%$ of SLS medium, basket at 100 rpm stirring speed and paddle at $25 \mathrm{rpm}$ stirring speed as apparatus for tablets and oral suspension, respectively, provided satisfactory results for both products. In these conditions, the BCZ stability was guarantee. The dissolution test was validated and showed to be specific, linear, precise and accurate. The $\%$ dissolved for all products was $>75 \%$ in $30 \mathrm{~min}$, and the suggested acceptance criteria could be $80 \%$ in $45 \mathrm{~min}$.

\section{REFERENCES}

1. Martindale; The Extra Pharmacopoeia, $31^{\text {th }}$ ed., Pharmaceutical Press: London, 1997.

2. British Pharmacopoeia Commission; British Pharmacopoeia, The Stationery Office, $4^{\text {th }}$ ed., London, 2003. 
3. Camillo-Coura, L.; Soli, A. S. V.; Bezerra, L. M. H.; O Hospital 1968, $74,1279$.

4. Arayne, M. S.; Sultana, N.; Siddiqui, F. A.; Pak. J. Pharm. Sci. 2006, 19, 326.

5. Arayne, M. S.; Sultana, N.; Siddiqui, F. A.; Chomatographia 2008, 67, 941.

6. Siddiqui, F. A.; Mirza, A. Z.; Zuberi, M. H.; Qureshi, F.; Med. Chem. Res. 2011, 20, 121.

7. Bakshi, M.; Singh, S.; J. Pharm. Biomed. Anal. 2002, 28, 1011.

8. Davydova, N.; Stippler, E.; Jin, P.; Giancaspro, G.; J. Pharm. Biomed. Anal. 2010, 53, 295.

9. Azarmi, S.; Roa, W.; Löbenberg, R.; Int. J. Pharm. 2007, 328, 12.

10. Shah, V. P.; Noory, A.; Noory, C.; McCullough, B.; Clarke, S.; Everett, R.; Naviasky, H.; Srinivasan, B. N.; Fortman, D.; Skelly, J. P.; Int. J. Pharm. 1995, 125, 99.
11. Frost, S. M. A.; Dissol. Tech. 2004, 11, 19.

12. Borgmann, S. H. M.; Parcianello, L.; Arend, M. Z.; Bajerski, L.; Cardoso, S. G.; Sci. Pharm. 2008, 76, 541.

13. The United States Pharmacopoeia (USP); $30^{\text {th }}$ ed., United States Pharmacopeial Convention: Rockeville, 2007.

14. International Conference on Harmonization (ICH); Harmonised tripartite guideline: Validation of analytical procedures: Text and methodology, Q2 (R1), 2005.

15. Rowe, R. C.; Sheskey, P. J.; Owen, S. C.; Handbook of Pharmaceutical Excipients, $5^{\text {th }}$ ed., Pharmaceutical Press: London, 2006.

16. The United States Pharmacopoeia, Pharmacopeial Forum 30, 2004, p. 351-363. 